\title{
Ambulation speed and corresponding mechanics are associated with changes in serum cartilage oligomeric matrix protein
}

\author{
W. Matt Denning \\ Brigham Young University, wmatt1215@yahoo.com \\ Michael Becker Pardo \\ Brigham Young University - Provo \\ Jason G. Winward \\ Brigham Young University - Provo \\ lain Hunter \\ Brigham Young University, iain_hunter@byu.edu \\ Sarah T. Ridge

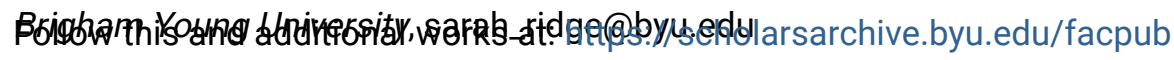 \\ Part of the Exercise Science Commons
}

See next page for additional authors

Original Publication Citation

Denning, W. Matt, et al. "Ambulation speed and corresponding mechanics are associated with changes in serum cartilage oligomeric matrix protein." Gait \& posture 44 (2016): 131-136.

\section{BYU ScholarsArchive Citation}

Denning, W. Matt; Pardo, Michael Becker; Winward, Jason G.; Hunter, lain; Ridge, Sarah T.; Hopkins, J. Ty; Reese, C. Shane; Parcell, Allen C.; and Seeley, Matthew K., "Ambulation speed and corresponding mechanics are associated with changes in serum cartilage oligomeric matrix protein" (2016). Faculty Publications. 2012.

https://scholarsarchive.byu.edu/facpub/2012

This Peer-Reviewed Article is brought to you for free and open access by BYU ScholarsArchive. It has been accepted for inclusion in Faculty Publications by an authorized administrator of BYU ScholarsArchive. For more information, please contact ellen_amatangelo@byu.edu. 


\section{Authors}

W. Matt Denning, Michael Becker Pardo, Jason G. Winward, lain Hunter, Sarah T. Ridge, J. Ty Hopkins, C. Shane Reese, Allen C. Parcell, and Matthew K. Seeley 


\title{
Ambulation speed and corresponding mechanics are associated with changes in serum cartilage oligomeric matrix protein
}

W. Matt Denning, Michael Becker Pardo, Jason G. Winward, Iain Hunter, Sarah Ridge, J. Ty Hopkins, C. Shane Reese, Allen C. Parcell, Matthew K. Seeley

\begin{abstract}
Because serum cartilage oligomeric matrix protein (COMP) has been used to reflect articular cartilage condition, we aimed to identify walking and running mechanics that are associated with changes in serum COMP. Eighteen subjects ( 9 male, 9 female; age $=23 \pm 2$ yrs.; mass $=68.3 \pm 9.6 \mathrm{~kg}$; height $=1.70 \pm 0.08 \mathrm{~m}$ ) completed 4000 steps on an instrumented treadmill on three separate days. Each day corresponded to a different ambulation speed: slow (preferred walking speed), medium ( $+50 \%$ of slow), and fast (+100\% of slow). Synchronized ground reaction force and video data were collected to evaluate walking mechanics. Blood samples were collected pre-, post-, 30-minute post-, and 60-minute post-ambulation to determine serum COMP concentration at these times. Serum COMP increased 29\%, 18\%, and 5\% immediately post ambulation for the fast, medium, and slow sessions $(p<0.01)$. When the speeds were pooled, peak ankle inversion, knee extension, knee abduction, hip flexion, hip extension, and hip abduction moment, and knee flexion angle at impact explained $61.4 \%$ of total variance in COMP concentration change $(p<0.001)$. These results indicate that $(1)$ certain joint mechanics are associated with acute change in serum COMP due to ambulation, and (2) increased ambulation speed increases serum COMP concentration.
\end{abstract}

\section{Keywords}

Walking, Running, Joint kinetics, Joint kinematics, Cartilage metabolism

\section{Introduction}

Articular cartilage bears mechanical load that is applied to a joint [1]. Mechanical load that results from physical activity can benefit cartilage by increasing structural components such as collagen and proteoglycans if the load involves typical magnitudes and locations of application [2]. Conversely, abnormal load (e.g., atypical load magnitudes and/or locations of application, or load rates) may damage cartilage [3]. Alterations in the regular balance of cartilage catabolism and anabolism can result from abnormal joint mechanics during physical activity [4].

Various types of physical activity (e.g., walking compared to running) likely results in different cartilage metabolic responses due to mechanical differences between the activities. For example, peak vertical ground reaction force $(G R F)$ increases from $1.0 \times$ body weight for walking at $1 \mathrm{~m} / \mathrm{s}$ 
to nearly $3.0 \times$ body weight for running at $6 \mathrm{~m} / \mathrm{s}$ [5]. Lower-extremity joint kinetics and kinematics also differ between ambulation speeds [6]. Increased GRF magnitude and the corresponding load rate [7], and knee joint kinematics and kinetics are associated with knee load and likely influence articular cartilage [8-10]. Sagittal and frontal plane ankle and hip kinetics have also been associated with compressive knee load during walking [11,12]. Although researchers have identified certain mechanical variables that may be related to joint load and resulting joint health, it is unclear which lower-extremity mechanical variables correlate with acute cartilage metabolism due to physical activity.

Cartilage oligomeric matrix protein (COMP) is an extracellular non-collagenous proteoglycan that helps organize the cartilage matrix, thereby contributing to the load bearing capability of articular cartilage [13]. An elevated resting serum COMP concentration level has been associated with osteoarthritis genesis and progression [14]. For able-bodied individuals, serum COMP concentration increases in response to physical activity. This increase is believed to be determined by magnitude and duration of the physical activity, and represent the metabolic effect of exercise-induced load [15-18]. Relative to walking, greater serum COMP concentration has been observed after running for the same duration [17,19]. It is unclear whether serum COMP concentration increases more for running, relative to walking, due to altered mechanics or step count differences (running involves more steps than walking when duration is fixed). No one has simultaneously measured serum COMP concentration and movement mechanics during ambulation across various speeds. Such a study could potentially provide additional insight regarding the effect of load magnitude and frequency, across a range of ambulation speeds on serum COMP concentration.

This study was 2-fold in purpose. The first purpose was to determine which mechanical variables correlate to acute changes in serum COMP concentration due to ambulation. The second purpose was to test the acute effect of ambulation speed on serum COMP, while controlling for step count. We hypothesized that (1) mechanical variables previously associated with knee load would correlate to serum COMP concentration increase, due to ambulation, and (2) that while controlling for step count, serum COMP concentration would increase more, immediately after fast ambulation compared to immediately after slow ambulation.

\section{Methods}

\subsection{Subjects}

Eighteen able-bodied volunteers ( 9 male, 9 female; age $=23 \pm 2$ yrs; mass $=68.3 \pm 9.6 \mathrm{~kg}$; height $=1.70 \pm 0.10 \mathrm{~m}$ ) participated in this cross-over designed study. No subject had experienced any arthritis or lower-extremity joint injury that would have compromised the integrity of the knee articular cartilage(e.g., ACL or meniscus tears), or was experiencing any lower-extremity pain at the time of data collection. Prior to participation, subjects provided informed consent. All procedures were approved by the appropriate institutional review board and complied with the Helsinki Declaration.

\subsection{Experimental protocol}

Subjects completed three data collection sessions (slow, medium, and fast) in a counterbalanced order (i.e., three subjects completed each of the six possible session orders) $24 \mathrm{~h}$ apart. During 
the slow session, subjects walked at a preferred speed that was determined on a day prior to the first data collection session. For the medium and fast sessions, subjects ambulated at speeds of $50 \%$ and $100 \%$ greater than their preferred speed. Average ambulation speeds for the slow, medium, and fast sessions were $1.32 \pm 0.12,1.99 \pm 0.19$, and $2.64 \pm 0.25 \mathrm{~m} / \mathrm{s}$. To control for step count, the number of steps were counted during each ambulation session using an optical measurement system (OptoJump Next, Microgate S.R.L., Bolzano, Italy). Once each subject completed 4000 steps, the data collection session ended. For all sessions, subjects ambulated on an instrumented treadmill (AMTI, Watertown, MA, USA) while wearing their own athletic shoes (Fig. 1).

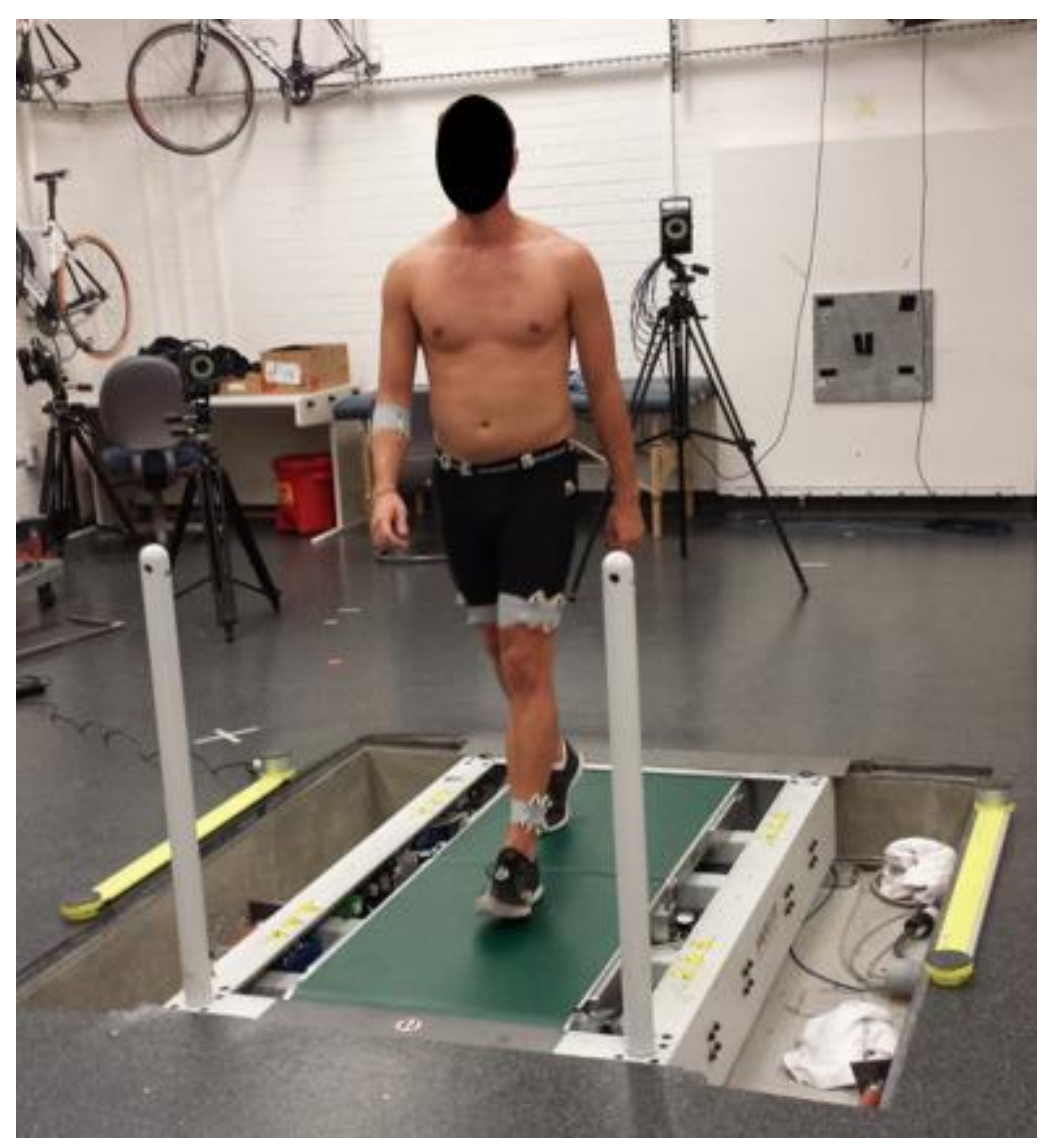

Fig. 1. Picture of subject during the slow data collection session.

At the beginning of each session, subjects rested on a chair for $30 \mathrm{~min}$ to minimize potential influence of preceding physical activity on serum COMP concentration [17]. Subjects then stood for $10 \mathrm{~min}$ while a researcher applied reflective markers to the subjects. Next, the pre-ambulation baseline blood sample was drawn (D1) and subjects then completed one of the three ambulation tasks. Blood samples were also drawn immediately after (D2), $30 \mathrm{~min}$ after (D3), and $60 \mathrm{~min}$ after (D4) the 4000 steps were completed. 


\subsection{Biomechanical variables}

Ten digital video cameras ( $240 \mathrm{~Hz}$; VICON, Santa Rosa, CA, USA) and an instrumented treadmill $(1200 \mathrm{~Hz})$ were used to record synchronized video and GRF data. Rigid clusters of four markers were attached bilaterally to the distal-lateral thigh and shank. Single markers were placed bilaterally over the anterior and posterior superior iliac spine, greater trochanter, medial and lateral femoral condyle, medial and lateral malleoli, posterior heel, dorsal midfoot, lateral foot, and between the second and third metatarsal. Subjects stood in anatomical position while a static standing trial was recorded. Subsequent dynamic measures were referenced to this static trial. Next, subjects performed standing leg motions to accurately calculate the hip joint center [20]. For each session, $15 \mathrm{~s}$ of GRF and coordinate data were recorded four different times throughout the session: 1000, 2000, 3000, and 4000 steps. Five gait cycles from each time were identified and discrete dependent variables were averaged across the 20 total gait cycles.

Coordinate and GRF data were imported into Visual 3D software (C-Motion, Germantown, MD, USA) and smoothed using a 4th order low-pass Butterworth filter; cutoff frequencies of 6, 7, and $8 \mathrm{~Hz}$ were determined using a standard residual analysis [21] and used for the slow, medium, and fast sessions. Using the static standing video, a three-dimensional model of the lower extremities and pelvis was created for each subject using previously described methods [22]. Joint angles were calculated using a Cardan rotation sequence (flexion/extension (x), abduction/adduction (y), and internal/external rotation (z)). Internal joint moments were calculated using GRF (smoothed using the aforementioned cutoff frequency [23]), joint angle, and anthropometric data [24]. In determining peak vertical GRF and average GRF load rate (calculated using previously described methods [25]), the GRF data were smoothed using a cutoff frequency of $50 \mathrm{~Hz}$ [26]. GRF, joint angle, and joint moment data were imported into MATLAB (The MathWorks, Natick, MA, USA) where the discrete dependent variables were identified using custom algorithms.

\subsection{Serum biomarkers}

All blood samples $(3 \mathrm{ml})$ were drawn from an antecubital vein using a 20-gauge shielded I.V. catheter (BD Vialon Insyte Autoguard, Becton Dickinson \& Co., Franklin Lakes, NJ, USA) that was placed during the 30-minute rest period. After insertion, the catheter was flushed with $1 \mathrm{ml}$ of isotonic saline $(0.9 \% \mathrm{NaCl})$ every $15 \mathrm{~min}$ to prevent clotting. Prior to collecting blood, a 1-ml waste sample was drawn. Blood samples were placed in EDTA vacutainers (BD Vacutainer K2 EDTA, Decton Dickinson \& Co., Franklin Lakes, NJ, USA), centrifuged for 15 min at $3000 \times g$, and then stored at $-20^{\circ} \mathrm{C}$. Serum COMP concentration was determined using manufacturer guidelines from a commercially available enzyme-linked immunosorbent assay (Quantikine Human COMP Immunoassay, R\&D Systems Inc., Minneapolis, MN, USA). Blood samples were analyzed in triplicate. Intra- and inter-assay coefficients of variation were $1.5 \%$ and $18.4 \%$ for a $165 \pm 37 \mathrm{ng} \mathrm{ml}^{-1}$ sample. We minimized inter-assay variation by comparing serum COMP concentration for each subject on the same plate.

\subsection{Statistical analysis}

Multiple linear regression analysis was used to evaluate the potential relationship between ambulation mechanics and serum COMP concentration change (D2 - D1). Because numerous mechanical variables were analyzed, we determined the optimal regression model using an 
information-based criterion selection process (Akaike information criteria). Plausible explanatory mechanical variables included: peak vertical GRF magnitude during stance and load rate, peak frontal and sagittal ankle, knee, and hip moments during stance, frontal, and sagittal knee angle at impact, and peak frontal and sagittal knee angle during weight acceptance (i.e., impact to peak knee flexion angle). A repeated measures mixed model analysis of covariance was used to compare serum COMP concentration between sessions across draws. Because baseline serum COMP levels differ between subjects and higher COMP concentration has been found in males [17], both baseline COMP and gender were used as covariates. If a session $\times$ draw interaction was detected, Tukey's post hoccomparisons were used to evaluate potential differences. Alpha levels for all statistical tests were set at 0.05 .

\section{Results}

\subsection{Multiple regression analysis}

Averages and $95 \%$ confidence intervals for the observed mechanical variables are presented in Table 1. In the regression analysis, each ambulation speed was included in the model as an indicator ' $I$ ' variable ( 1 or 0$)$. The analysis produced the following pooled model (included all speeds) that relates joint mechanics and serum COMP concentration increase, due to ambulation:

$\mathrm{y}=\beta 0$ Icond $=$ slow $+\beta 0$ Icond $=$ medium $+\beta 0$ Icond $=$ fast $+\beta 1$ ankleinvesionmoment $+\beta 2$ kneeextensionmoment $+\beta$ 3 kneeabductionmoment $+\beta 4$ hipflexionmoment $+\beta 5$ hipextensionmoment $+\beta 6$ hipabductionmoment $+\beta 7 \mathrm{kneef}$ lexionangleatimpact.

Table 1. Average (95\% confidence interval) kinematic and kinetic (normalized to body mass) variables for each session (slow, medium, and fast). Positive values represent knee flexion and adduction. Knee angle for weight acceptance indicate peak value during weight acceptance. Joint moments are each represented using a positive value.

\begin{tabular}{|c|c|c|c|}
\hline & Slow & Medium & Fast \\
\hline Knee flexion angle at impact $\left(^{\circ}\right)$ & $\begin{array}{c}-2.1 \\
(-4.7-0.5)\end{array}$ & $\begin{array}{c}6.9 \\
(4.0-9.8)\end{array}$ & $\begin{array}{c}9.3 \\
(6.3-12.3)\end{array}$ \\
\hline Knee adduction angle at impact $\left(^{\circ}\right)$ & $\begin{array}{c}0.6 \\
(-0.4-1.5)\end{array}$ & $\begin{array}{c}0.2 \\
(-1.2-1.5)\end{array}$ & $\begin{array}{c}-0.3 \\
(-1.7-1.1)\end{array}$ \\
\hline Knee flexion angle for weight acceptance $\left(^{\circ}\right)$ & $\begin{array}{c}15.4 \\
(12.7-18.2)\end{array}$ & $\begin{array}{c}35.4 \\
(33.5-37.4)\end{array}$ & $\begin{array}{c}38.8 \\
(36.7-40.9)\end{array}$ \\
\hline Knee adduction angle for weight acceptance $\left(^{\circ}\right)$ & $\begin{array}{c}3.3 \\
(2.1-4.4)\end{array}$ & $\begin{array}{c}4.9 \\
(2.5-7.3)\end{array}$ & $\begin{array}{c}4.9 \\
(2.7-7.1)\end{array}$ \\
\hline Peak vertical GRF (BW) & $\begin{array}{c}1.21 \\
(1.18-1.24)\end{array}$ & $\begin{array}{c}2.24 \\
(2.16-2.32)\end{array}$ & $\begin{array}{c}2.45 \\
(2.35-2.55)\end{array}$ \\
\hline
\end{tabular}




\begin{tabular}{|c|c|c|c|}
\hline & Slow & Medium & Fast \\
\hline Load rate $\left(\mathrm{BW}^{*} \mathrm{~s}^{-1}\right)$ & $\begin{array}{c}5.97 \\
(5.67-6.26)\end{array}$ & $\begin{array}{c}15.45 \\
(13.71-17.19)\end{array}$ & $\begin{array}{c}19.19 \\
(17.13-21.24)\end{array}$ \\
\hline Peak plantar flexion moment $\left(\mathrm{Nm}^{*} \mathrm{~kg}^{-1}\right)$ & $\begin{array}{c}1.53 \\
(1.45-1.61)\end{array}$ & $\begin{array}{c}2.25 \\
(2.05-2.44)\end{array}$ & $\begin{array}{c}2.71 \\
(2.50-2.92)\end{array}$ \\
\hline Peak ankle Inversion moment $\left(\mathrm{Nm}^{*} \mathbf{k g}^{-1}\right)$ & $\begin{array}{c}0.25 \\
(0.22-0.29)\end{array}$ & $\begin{array}{c}0.32 \\
(0.27-0.37)\end{array}$ & $\begin{array}{c}0.37 \\
(0.31-0.44)\end{array}$ \\
\hline Peak knee flexion moment $\left(\mathrm{Nm}^{*} \mathbf{k g}^{-1}\right)$ & $\begin{array}{c}0.32 \\
(0.28-0.37)\end{array}$ & $\begin{array}{c}0.35 \\
(0.29-0.40)\end{array}$ & $\begin{array}{c}0.38 \\
(0.32-0.45)\end{array}$ \\
\hline Peak knee extension moment $\left(\mathrm{Nm}^{*} \mathbf{k g}^{-1}\right)$ & $\begin{array}{c}0.73 \\
(0.63-0.83)\end{array}$ & $\begin{array}{c}2.24 \\
(2.03-2.25)\end{array}$ & $\begin{array}{c}2.45 \\
(2.25-2.65)\end{array}$ \\
\hline Peak knee abduction moment $\left(\mathrm{Nm}^{*} \mathrm{~kg}^{-1}\right)$ & $\begin{array}{c}0.46 \\
(0.38-0.54)\end{array}$ & $\begin{array}{c}0.75 \\
(0.63-0.87)\end{array}$ & $\begin{array}{c}0.83 \\
(0.69-0.97)\end{array}$ \\
\hline Peak hip flexion moment $\left(\mathrm{Nm}^{*} \mathrm{~kg}^{-1}\right)$ & $\begin{array}{c}0.66 \\
(0.56-0.75)\end{array}$ & $\begin{array}{c}0.59 \\
(0.53-0.65)\end{array}$ & $\begin{array}{c}0.60 \\
(0.52-0.67)\end{array}$ \\
\hline Peak hip extension moment $\left(\mathrm{Nm}^{*} \mathbf{k g}^{-1}\right)$ & $\begin{array}{c}0.65 \\
(0.52-0.78)\end{array}$ & $\begin{array}{c}0.76 \\
(0.66-0.87)\end{array}$ & $\begin{array}{c}0.93 \\
(0.82-1.04)\end{array}$ \\
\hline Peak hip abduction moment $\left(\mathrm{Nm}^{*} \mathrm{~kg}^{-1}\right)$ & $\begin{array}{c}0.93 \\
(0.85-1.01)\end{array}$ & $\begin{array}{c}1.57 \\
(1.47-1.66)\end{array}$ & $\begin{array}{c}1.63 \\
(1.51-1.75)\end{array}$ \\
\hline
\end{tabular}

The regression model explained $61.4 \%$ (adjusted $R^{2}=0.54$ ) of the total variance in serum COMP increase $(F=7.8 ; p<0.001)$, due to ambulation. The regression coefficients are presented in Table 2.

Table 2. Regression coefficients that describe the associations between significant mechanical variables (as identified by the regression model) and serum COMP increase due to ambulation.

$\begin{array}{lrrrrr} & \boldsymbol{\beta} & \boldsymbol{\beta} \text { Error } & \text { Lower 95\% } & \text { Upper 95\% } & p \text {-value } \\ \text { Slow } & 46.8 & 19.0 & 9.6 & 84.1 & 0.02 \\ \text { Medium } & 83.2 & 29.4 & 24.2 & 142.4 & 0.001 \\ \text { Fast } & 94.5 & 31.0 & 32.0 & 157.0 & 0.004\end{array}$




\begin{tabular}{lrrrrr} 
& \multicolumn{1}{c}{$\boldsymbol{\beta}$} & $\boldsymbol{\beta}$ Error & Lower 95\% & Upper 95\% & $\boldsymbol{p}$-value \\
AIN & 28.1 & 21.5 & -15.1 & 71.4 & 0.20 \\
KE & 4.0 & 6.4 & -8.9 & 16.8 & 0.54 \\
KAB & 29.9 & 15.9 & -2.2 & 61.9 & 0.07 \\
HF & -34.5 & 13.5 & -61.7 & -7.3 & 0.01 \\
HE & 13.3 & 9.5 & -5.9 & 32.4 & 0.17 \\
HAB & -55.2 & 18.6 & -92.7 & -17.8 & 0.01 \\
KFI & -0.6 & 0.4 & -1.5 & 0.2 & 0.13
\end{tabular}

$\mathrm{AIN}=$ peak internal ankle inversion moment; $\mathrm{KE}=$ peak internal knee extension moment; $\mathrm{KAB}=$ peak internal knee abduction moment; $\mathrm{HF}=$ peak internal hip flexion moment; $\mathrm{HE}$ = peak internal hip extension moment; $\mathrm{HAB}=$ peak internal hip abduction moment; KFI = knee flexion angle at heel strike.

\subsubsection{Serum COMP and ambulation speed}

For D2, average serum COMP concentration for the fast session was $9 \%$ and $24 \%$ greater than for the medium $(p=0.001)$ and slow $(p<0.001)$ sessions. Average serum COMP concentration for the medium session was $14 \%$ greater than for the slow session $(p<0.001$; Table 3$)$. As a main effect, session influenced serum COMP concentration. Average serum COMP concentration for the fast session was $6 \%$ and $7 \%$ greater than for the medium $(p=0.009)$ and slow $(p=0.002)$ sessions (Table 3 ). Time, as a main effect, also influenced serum COMP concentration. Serum COMP concentration increased 29\%, 18\%, and 5\% immediately post ambulation for the fast, medium, and slow sessions, respectively (Table 3 ). When pooled across all sessions, average serum COMP concentration for D2 was $15 \%$ greater than D1 $(p<0.001)$, while serum COMP concentration for D3 and D4 was 9\% and 11\% less than D1 $(p<0.01)$.

Table 3. Average (95\% confidence interval) absolute serum COMP concentration $\left(\mathrm{ng}^{*} \mathrm{ml}^{-1}\right)$ for each session and draw.

$\begin{array}{ccccc} & \text { Slow } & \text { Medium } & \text { Fast } & \text { Average } \\ \text { Draw 1 } & 121.5 & 122.9 & 122.9 & 122.4 \\ & (116.0-126.9) & (117.5-128.4) & (117.4-128.4) & (118.0-126.8) \\ \text { Draw 2 } & 127.9^{\ddagger} & & & \\ & (122.5-133.4) & (140.0-150.8) & (152.8-163.6) & (139.4-148.2)\end{array}$




$\begin{array}{lcccc} & \text { Slow } & \text { Medium } & \text { Fast } & \text { Average } \\ \text { Draw 3 } & 113.4 & 109.3 & 114.8 & 112.5^{*} \\ & (107.9-118.8) & (103.9-114.8) & (109.5-120.5) & (108.1-116.9) \\ \text { Draw 4 } & 114.9 & & & 110.8^{*} \\ & (109.5-120.3) & (99.3-110.2) & (107.3-118.1) & (106.4-115.2) \\ \text { Average } & 119.4^{*} & 120.6^{*} & 127.2 & \\ & (115.6-123.3) & (116.8-124.4) & (123.4-131.0) & \\ * \text { Significantly different }(p<0.05) \text { from baseline serum coMP concentration for each session. Significantly different } \\ (p<0.05) \text { between sessions at each draw. Significantly different }(p<0.05) \text { from averaged fast session. }\end{array}$

\section{Discussion}

We aimed to identify mechanical characteristics of ambulation that are associated with acute serum COMP concentration increase, due to ambulation, and determine whether ambulation speed acutely influences serum COMP concentration when step count is controlled. We hypothesized that serum COMP increase would correlate to specific mechanical characteristics that have been theorized to reflect knee load during ambulation. In support of this hypothesis, peak ankle inversion, knee extension and abduction, and hip extension moment positively correlated with serum COMP change, while peak hip flexion and abduction moments, and knee flexion angle at impact negatively correlated with serum COMP. Combined, these mechanical characteristics explained $61 \%$ of the variance for serum COMP increase due to ambulation. We also hypothesized that serum COMP change would increase as ambulation speed increased. The data also supported this hypothesis: serum COMP concentration increased more after fast ambulation than after medium and slow ambulation. However, serum COMP concentration was not elevated 30 min after ambulation for any speed.

The present findings suggest that frontal and sagittal plane knee kinetics and kinematics influence serum COMP concentration. The observed relationship between knee extension moment and serum COMP increase corroborates computational modeling data that indicate compressive knee force during the first half of stance is primarily caused by quadriceps activation [27]. Similarly, maximum sagittal-plane knee torque has been correlated with patella cartilage volume change [28]. Conversely, Kersting et al., [28] found no association between peak sagittal-plane knee torque and serum COMP change. This was perhaps because the COMP changes observed by Kersting et al. [28] were relatively small, potentially for two reasons. First, Kersting et al. [28] observed trained runners who likely had higher pre-exercise COMP concentration than our subjects [29]. Second, Kersting et al. [28] waited 25 min to collect the first post-exercise blood sample, which probably resulted in a lower post-exercise COMP concentration.

The present knee angle data fit with previous reports that knee flexion angle at impact significantly correlates with cartilage thickness [9]. Increased knee flexion at impact may reduce GRF and knee range of motion, which could decrease knee loads [8]. Conversely, increased knee flexion at impact may require greater knee extensor muscle activity and potentially result in 
greater knee compressive forces. Further research is needed to better understand the influence of knee angle, at impact, on knee articular cartilage. Importantly, the negative mean knee flexion angle that is presently reported for impact during the slow condition indicates knee hyperextension, and likely indicates that the knee markers were consistently placed too posteriorly during the static frame. We acknowledge that a contributor to error in gait analysis is due to marker placement accuracy. However, because the same researcher placed all markers for all subjects during all of the data collection sessions, this potential error is unlikely to have affected the results of the correlational analyses that were performed to accomplish the primary purpose of this study.

The present data also indicate that hip joint moments influence serum COMP change, supporting the established idea that hip mechanics influence knee load. For example, increased hip flexion moment during push-off pulls the thigh off the ground and reduces knee load [12], and possibly reduces serum COMP increase due to ambulation. Further, decreased hip abduction torque during stance causes excessive pelvic drop of the contralateral swing leg, medial center of mass shift, and increased medial tibiofemoral joint load [11]. This may be one reason why increased hip abduction moment was associated with decreased serum COMP change. All of this implies that stronger hip musculature may effectively decrease knee load and corresponding acute knee cartilage metabolism.

Fitting with previous research $[15,17,19]$, the present results show that physical activity intensity influences the magnitude of serum COMP increase. The present results also indicate that serum COMP concentration returned to baseline no later than 30 min after ambulating 4000 steps, independent of ambulation speed. Serum COMP has been shown to return to pre-exercise levels within 30 min after a 30-minute walk [17], and 60 min after a 30-minute run [19]. Our data suggest that these differences in COMP increase duration are at least partially due to differing step counts. For example, running $30 \mathrm{~min}$ at $2.2 \mathrm{~m} / \mathrm{s}$ requires an average of 4262 steps [19], while a 30-minute walk at $1.5 \mathrm{~m} / \mathrm{s}$ requires only 3507 steps [17]. Because our subjects ambulated 4000 steps for all speeds and no between-speed differences were observed for COMP increase duration, we conclude that COMP increase duration is influenced by step count, not load magnitude. This is the first study to show that when step count is controlled, serum COMP concentration returns to pre-exercise levels within $30 \mathrm{~min}$, independent of ambulation speed.

Average serum COMP concentrations 30 and 60 min post-ambulation were less than at baseline. Although this finding fits with a resting protocol [17], it contradicts similar COMP data that were collected following ambulation [17,19]. We believe this occurred because of methodological differences. Although subjects rested for $30 \mathrm{~min}$ to minimize the influence of preceding activity on serum COMP, the baseline blood sample was drawn after subjects stood for 10 min while reflective markers were placed on specific bony landmarks. This 10-minute standing period likely increased load placed on articular cartilage and elevated our baseline measures. Future researchers who simultaneously measure movement mechanics and serum biomarkers that are sensitive to load should consider completing all subject preparation, like reflective marker placement, before a rest period.

The interpretation of our serum COMP concentration results warrants caution for three reasons. First, additional mechanical variables could have been included as potential predictors in our model (e.g., GRF impulse or joint contact force). This may have improved our results and further 
examination of this idea is warranted. Second, the exact origin of the COMP cannot be definitively determined via serum analysis. COMP is predominantly found in articular cartilage, however, it is also found in ligaments, tendons, and menisci [30]. It is unclear which joint or tissue contributed to the observed serum COMP change, although researchers have speculated that serum COMP increase is at least partially due to knee load [19,28]. Third, the meaning of increased serum COMP following physical activity is unclear. In healthy subjects, previous serum COMP [18] and MRI data [28] suggest that increased serum COMP concentration reflects acute cartilage breakdown due to repetitive loads associated with ambulation. Also, increased serum COMP concentration is thought to indicate normal cartilage turnover $[15,17,19]$. Because our subjects were healthy and young, and the exercise interventions were low demand and of a short duration, we assume that the observed serum COMP increases represent normal cartilage metabolism. More research is needed to distinguish whether serum COMP increase, due to physical activity for young asymptomatic adults, represents normal cartilage turnover or unhealthy articular cartilage degradation.

In summary, some specific measures of lower-extremity joint mechanics during ambulation are associated with serum COMP increase due to ambulation. Combining some of these variables appears to effectively account for part of the variance in this serum COMP concentration change due to ambulation; when combined, several specific variables accounted for $61 \%$ of the variance in serum COMP increase due to ambulation. If a researcher or clinician assumes that serum COMP is a valid representation of cartilage metabolism, these characteristics of ambulation could be used as one noninvasive tool to consider when assessing acute cartilage metabolism that results from ambulation. Also, if step count is held constant, increased ambulation speed acutely results in increased cartilage metabolism.

\section{Conflict of interest}

There are no conflicts of interest associated with this research project.

\section{References}

[1] Ateshian GA, Wang H. A theoretical solution for the frictionless rolling contact of cylindrical biphasic articular cartilage layers. J Biomech 1995;28:1341-55.

[2] Arokoski JPA, Jurvelin JS, Vaatainen U, Helminen HJ. Normal and pathological adaptations of articular cartilage to joint loading. Scand J Med Sci Sports 2000;10:186-98.

[3] L'Hermette MF, Tourny-Chollet C, Polle G, Dujardin FH. Articular cartilage, degenerative process, and repair: current progress. Int J Sports Med 2006;27:738-44.

[4] Gahunia HK, Pritzker KPN. Effect of exercise on articular cartilage. Orthop Clin N Am 2012;43:18799.

[5] Nilsson J, Thorstensson A. Ground reaction forces at different speeds of human walking and running. Acta Physiol Scand 1989;136:217-27.

[6] Schache AG, Blanch PD, Dorn TW, Rosemond TD, Pandy MG. Effect of running speed on lower limb joint kinetics. Med Sci Sport Exerc 2011;43:1260-71.

[7] Whittle MW. Generation and attenuation of transient impulsive forces beneath the foot: a review. Gait Posture 1999;10:264-75.

[8] Creaby MW, Hunt MA, Hinman RS, Bennell KL. Sagittal plane joint loading is related to knee flexion in osteoarthritic gait. Clin Biomech 2013;28:916-20. 
[9] Koo S, Rylander JH, Andriacchi TP. Knee joint kinematics during walking influences the spatial cartilage thickness distribution in the knee. J Biomech 2011;44:1405-9.

[10] Zhao D, Banks SA, Mitchell KH, D'Lima DD, Colwell Jr CW, Fregly BJ. Correlation between the knee adduction torque and medial contact force for a variety of gait patterns. J Orthop Res 2007;25:789-97.

[11] Chang A, Hayes K, Dunlop D, Song J, Hurwitz D, Cahue S, et al. Hip abduction moment and protection against medial tibiofemoral osteoarthritis progression. Arthritis Rheumatol 2005;52:3515-9.

[12] Robon MJ, Perell KL, Fang M, Guererro E. The relationship between ankle plantar flexor muscle moments and knee compressive forces in subjects with and without pain. Clin Biomech 2000;15:522-7.

[13] Tseng S, Reddi AH, Di Cesare PE. Cartilage oligomeric matrix protein (COMP): a biomarker of arthritis. Biomark Insights 2009;4:33-44.

[14] Chaganti RK, Kelman A, Lui L, Yao W, Javaid MK, Bauer D, et al. Change in serum measurements of cartilage oligomeric matrix protein and association with the development and worsening of radiographic hip osteoarthritis. Osteoarthr Cartil 2008;16:566-71.

[15] Denning WM, Woodland S, Winward JG, Leavitt MG, Parcell AC, Hopkins JT, et al. The influence of experimental anterior knee pain during running on electromyography and articular cartilage metabolism. Osteoarthr Cartil 2014;22:1111-9.

[16] Kim HJ, Lee YH, Kim CK. Changes in serum cartilage oligomeric matrix protein (COMP), plasma CPK and plasma hs-CRP in relation to running distance in a marathon $(42.195 \mathrm{~km})$ and an ultramarathon (200 km) race. Eur J Appl Physiol 2009;105:765-70.

[17] Mündermann A, Dyrby CO, Andriacchi TP, King KB. Serum concentration of cartilage oligomeric matrix protein (COMP) is sensitive to physiological cyclic loading in healthy adults. Osteoarthr Cartil 2005;13:34-8.

[18] Niehoff A, Kersting UG, Helling S, Dargel J, Maurer J, Thevis M, et al. Different mechanical loading protocols influence serum cartilage oligomeric matrix protein levels in young healthy humans. Eur J Appl Physiol 2010;110:651-7.

[19] Niehoff A, Muller M, Bruggemann L, Savage T, Zaucke F, Eckstein F, et al. Deformational behaviour of knee cartilage and changes in serum cartilage oligomeric matrix protein (COMP) after running and drop landing. Osteoarthr Cartil 2011;19:1003-10.

[20] Schwartz MH, Rozumalski A. A new method for estimating joint parameters from motion data. J Biomech 2005;38:107-16.

[21] Winter DA. Biomechanics and motor control of human movement. New York: John Wiley \& Sons; 1990.

[22] Ford KR, Shapiro R, Myer GD, Van Den Bogert AJ, Hewett TE. Longitudinal sex differences during landing in knee abduction in young athletes. Med Sci Sport Exerc 2010;42:1923-31.

[23] Bisseling RW, Hof AL. Handling of impact forces in inverse dynamics. J Biomech 2006;39:243844.

[24] Dempster W. Space requirements of the seated operator. OH: Wright-Patterson Air Force Base; 1955 [WADC Technical Report (TR-55-159)].

[25] Milner CE, Ferber R, Pollard CD, Hamill J, Davis IS. Biomechanical factors associated with tibial stress fracture in female runners. Med Sci Sport Exerc 2006;38:323-8.

[26] Bonacci J, Saunders PU, Hicks A, Rantalainen T, Vicenzino BG, Spratford W. Running in a minimalist and lightweight shoe is not the same as running barefoot: a biomechanical study. Brit $\mathbf{J}$ Sport Med 2013;47:387-92. 
[27] Pandy MG, Andriacchi TP. Muscle and joint function in human locomotion. Annu Rev Biomed Eng 2010;12:401-33.

[28] Kersting UG, Stubendorff JJ, Schmidt MC, Bruggemann GP. Changes in knee cartilage volume and serum COMP concentration after running exercise. Osteoarthr Cartil 2005;13:925-34.

[29] Neidhart M, Mu“ller-Ladner U, Frey W, Bosserhoff AK, Colombani PC, FreyRindova P, et al. Increased serum levels of non-collagenous matrix proteins (cartilage oligomeric matrix protein and melanoma inhibitory activity) in marathon runners. Osteoarthr Cartil 2000;8:222-9.

[30] Muller G, Michel A, Altenburg ECOMP. (cartilage oligomeric matrix protein) is synthesized in ligament, tendon, meniscus, and articular cartilage. Connect Tissue Res 1998;39:233-44. 